\title{
Forthcoming in Social Theory and Practice
}

WAIVING JURY DELIBERATION: THE HUMILITY ARGUMENT

\begin{abstract}
This article argues that, given the current pervasive uncertainty about the reliability of jury deliberation, we ought to treat it with epistemic humility. I further argue that epistemic humility should be expressed and enforced by turning jury deliberation from a mandatory rule of the jury trial to a waivable right of the defendant. I consider two main objections to my argument: the first one concerns the putative self-defeatingness of humility attitudes; the second objection points to the burdensomeness of granting an unconditional jury deliberation waiver to the defendant.
\end{abstract}

Key-words: jury trials, jury deliberation, deliberation, voting, epistemic humility, waivable rights

More than twenty years ago, Lynn Sanders argued that we should discard deliberation. ${ }^{1}$ Sanders focused on jury deliberation, which she took to be paradigmatic of deliberation in general. Drawing on various empirical studies, she claimed that the jurors' process of deliberating is infused with biases and permeated with power relations that both compromise their equal standing in relation to each other and undermine the epistemic quality of deliberative outcomes. Jury deliberation, said Sanders, should be discarded because it faces an "epistemological problem" it cannot solve by itself. The problem is that "prejudice and privilege do not emerge in deliberative settings as bad reasons, and they are not countered by good arguments," mainly because the former are "too sneaky, invisible and pernicious for that reasonable process" (353).

This article argues that we are right to have resisted Sanders's skepticism all the way to abolishing jury deliberation, but that we are wrong in not articulating a 
normative position that adequately reflects the epistemic problems plaguing jury deliberation. Pace Sanders, I will show that jury deliberation is not all bad, and that the current evidence we have about its reliability is pervasively mixed. Jury deliberation is, on the whole, both epistemically good and bad, and persistently so. This uncertainty presents scholars seeking to justify it with a puzzle.

There seem to be only two solutions to this puzzle: either we treat jury deliberation with skepticism and advocate for its abolition, or we endorse an attitude of optimism and keep it as a basic procedure of the jury trial. ${ }^{2}$ My claim is that the alternative these two positions underlie is too narrow. I will, instead, argue in favor of epistemic humility as an intermediate position between a skeptical rejection and an optimistic defense of the status quo. I will also argue that humility about jury deliberation requires that we stop imposing it as a mandatory rule of the jury trial. Acknowledging that the jury is a legitimate institution, I suggest that an adequate way of expressing humility about deliberation is to turn it from a mandatory rule into a waivable right of the defendant.

The article is structured as follows. In Section I, I present the evidence grounding the uncertainty about jury deliberation and explain why this presents us with an important problem. Section II moves on to argue that epistemic humility is an adequate way of acknowledging this uncertainty. In Section III, I unpack one possible institutional implication of the humility argument and contend that humility about jury deliberation can be expressed by changing its legal status from a mandatory rule of jury trials to a waivable right of the defendant. The waivability proposal is that the defendant be given a choice between receiving a deliberative or a non-deliberative verdict. Finally, in Section IV, I address two possible objections.

Before moving on to the next section, two preliminary remarks are in order. First, I will focus on jury deliberation and, in particular, on deliberation in criminal jury trials. I do not take issue with deliberation in general. This is because I think that

2 This is endorsed most explicitly by Ho (2013). 
there are distinctions between different deliberative practices that will make any extrapolation particularly difficult. 3

Second, my assessment of jury deliberation prioritizes the epistemic values of reliability and accuracy over other normative considerations. This does not mean that I do not acknowledge that jury deliberation can be differently grounded - for instance, by appealing to democratic desiderata like civic participation or citizen competence. But the emphasis on epistemic considerations is based on the assumption that, no matter what other values it should track, jury deliberation cannot be justified unless it is epistemically warranted. Imagine a trial procedure that regularly undermined the probability of reaching accurate decisions or that behaved in an epistemically random manner. Such a procedure would be considered unjustified, thus reflecting our shared beliefs about the centrality of truth in accounting for any trial procedures.

\section{THE UNCERTAINTIES OF JURY DELIBERATION}

The findings about jury deliberation are mixed, thus commending uncertainty about whether jury deliberation can, on the whole, be considered reliable. I identify five sources of uncertainty, although I admit that there might be more and that some of the ones I examine here might be overlapping.

The first one concerns the impact that deliberation has on jurors' reasoning skills. McCoy, Nunez \& Dammeyer (1990) have found that, after a period of deliberation on a murder case, jurors proved more nuanced in their interpretation of the facts and were better at evaluating the conflicting evidence they were confronted with. This is however hard to reconcile with the fact that group deliberation has also been shown to stifle the exercise of jurors' individual reasoning. This latter phenomenon is typically known as the reputational cascade effect, whereby individuals rely on or repeat what other seemingly more competent jurors think (Sunstein 2006:

3 This article focuses mostly on US criminal juries, although my argument can, if properly specified, be applied to Canada and the UK. 
92). These findings give us non-trivial reasons to think that the perfecting effect of deliberation on jurors' inferential competence may, at times, be more apparent than real.

The second source of uncertainty is about whether deliberation can strengthen jurors' capacity to identify accurate evidence and detect deceit. Salerno \& Mccauley (2009) found that group deliberation improved jurors' ability to detect flawed scientific expertise by increasing the truth-discriminating virtues of cross-examination during trial. In particular, they found that deliberation had a more substantial impact on individuals who initially lacked the motivation to process experts' testimony. The explanation for this post-deliberative upgrade might be that "jurors who processed the cross-examination deeply might force other jurors who either distrusted, did not understand, or did not pay attention to cross-examination to incorporate it into their judgments" (Salerno, Mccauley 2009: 5). But the same authors admit that it remains unclear whether deliberation is bolstering one's motivation for detecting inaccurate expertise or whether jurors with poor cognitive motivation are merely giving in to the pressures of the more cognitively active ones. The logic of these latter findings is also at odds with Kraus and Lee's earlier study (2003), showing that, in the context of a capital sentencing trial, deliberation had (at best) a very weak impact on identifying accurate expertise.

The third source of uncertainty pertains to the relation between deliberation and its role in dismissing inadmissible evidence in general, not only expertise. In a simulated case of armed robbery, Kerwin \& Shaffer (1994) found that deliberating juries were more effective than non-deliberating ones at following judicial instructions in discarding inadmissible evidence. London \& Nunez (2000: 937) obtained similar findings in a mock sexual assault case, which prompted them to conclude that "the impact of inadmissible evidence was lessened following jury deliberations". More generally, Steblay et al.'s (2006: 486) meta-study found some evidence that deliberation can "diminish the influence of otherwise damaging inadmissible 
information”. However, this contradicts Steblay et al.'s (1999) previous meta-study concluding that deliberation could not eliminate the influence of pre-trial publicity on the jury's final decision. It is also difficult to reconcile it with Thompson, Fong and Rosenhan's (1981) or Carretta \& Moreland's (1983) findings that deliberation helped discard inadmissible evidence presented by the prosecution, but was unable to do so when the evidence came from the defense.

Fourth, jury deliberation plays an uncertain role in offsetting any biases and stereotypes that may enter the jury's decision-making process. For example, Izzett \& Leginski (1974) found that deliberation lowered the influence of a defendant's unattractiveness on the verdict. Kaplan \& Miller (1978) showed that deliberation is effective at countering situational biases, like the ones induced by an obnoxious lawyer during trial. These findings were nonetheless later nuanced by Kerr, Niedermeier \& Kepler (1999), who found that deliberation counters biases only in extreme cases, in which the probability of conviction is either very high or very low, but increases their influence in moderate cases. Similarly, in an earlier study, Kramer, Kerr \& Caroll (1990) found that the impact of negative pre-trial publicity on the verdict was increased through deliberation, a phenomenon they attributed to less confident jurors being more easily persuaded to change their views at the end of group deliberations.

More recently, Haegerich, Salerno \& Bottoms (2013) produced evidence that pre-trial stereotypes held by individual jurors were minimized by jury deliberation. But this study also showed that when stereotypes were activated during trial proceedings, deliberation actually exacerbated, rather than moderating them. This led the authors to conclude that "the impact of jurors' stereotypes on case decisions could be 'maximized' or 'minimized' by the deliberation process" (Haegerich, Salerno \& Bottoms 2013: 81).

The picture becomes blurrier when we take into account Takada \& Murata's (2014) study showing that group deliberation can increase the impact of framing effects on the jury's verdict or Robert MacCoun's (1990) earlier experiment showing that a defendant's physical attractiveness influenced the jurors only after group 
deliberation. Still more confusingly, this latter study was contradicted by Patry's (2008: 731) more recent finding that "deliberation seemed to eliminate a predeliberation bias in favor of the attractive defendant”.

Fifth, and finally, it is uncertain whether deliberation improves the mnemonic quality of jury decisions. Hastie, Penrod \& Pennington (1983: 78) found that deliberation substantially improves the deliberators' recall reliability. Only $59 \%$ of individual jurors were accurate in their memory of the trial testimony, whereas the jury's post-deliberative accuracy rate was 93\%. Pritchard \& Keenan (2002) confirmed this difference, although their results were considerably more modest. Jury deliberation improved the accuracy of recall by $1 \%$ for central information and by $6 \%$ for peripheral - that is, outcome-irrelevant - information. They conjectured that such minor effects happen because "highly confident individuals, who were slightly more likely to be controlling jury deliberation, were not always the most accurate" (Pritchard \& Keenan 2002: 600).

More generally, a growing body of findings shows that group collaboration sometimes diminishes recall performance (Basden et al. 1997; Weldon, Blair, Huebsch 2000; Maki et. al. 2008). For example, Hirst, Coman \& Stone (2012: 164) argue that group interaction is likely to improve the group's collective memory, but only for groups whose members know each other and who are connected through stable relations. Furthermore, they suggest that, because of one or a few persons leading the group's interactions (a phenomenon they call "the dominant narrator effect"), the other members' individual memories might simply be excluded from the deliberative process. The authors conclude that "there is no reason to believe that 12 people working together to remember the testimony from a trial will remember it more accurately than 1 person remembering on his or her own" (Hirst, Coman \& Stone 2012: 178).

Less speculatively, Nunez, McCrea \& Culhane (2011: 445) worry that, for various reasons - like a failure to communicate one's opinion properly, the 
disorganized pace of group discussions or social loafing - increasing the size of groups could reduce "the perceived responsibility any one individual feels for contributing to the discussion, and so vital information may not enter into the discussion”. It is not clear whether this means that accuracy might be improved by reducing the size of juries. What is clear is that such a claim is at odds with the more widely shared belief that the main advantage of deliberation resides in the diversity of views that it brings together.

Before moving to the next section, some remarks are in order. The first is that the currently available evidence attests that jury deliberation is not consistently reliable. Consequently, we cannot argue ex ante that it is more likely than not to result in accurate verdicts. But studies show something more specific, namely, that the uncertainty surrounding jury deliberation is relative, not absolute: its mixed credentials are narrowly assessed in relation to a strictly voting procedure, whereby individual jurors judge the case themselves and then take a non-deliberative decision on the verdict.

This observation is important because it indicates that our uncertainty about jury deliberation does not cut sufficiently deep to warrant an attitude of wholesale skepticism. For all we know, deliberation remains epistemically better than a significant number of alternative procedures. It is surely better than deciding the outcome of the trial randomly - say, by flipping a coin - or through some patently dubious procedure like the ordeal. Saying that jury deliberation is uncertain therefore means that it is uncertain compared to the process of jurors voting on the verdict individually.

The second remark is that the mixed credentials of jury deliberation as a decision-making procedure are not systematically associated with and, consequently, cannot be attributed to any relevant decision-taking rule whereby final verdicts are established. Jury deliberation has been shown to perform both well and badly for the same decision rule (Hastie, Penrod \& Pennington 1983; Hirst, Coman \& Stone 2012), 
which is to say that changing the latter - most relevantly, substituting a qualified majority for a unanimity rule 4 - neither improves nor impairs the epistemic quality of jury deliberation. 5

The third remark is that uncertainty about reliability is not specific to jury deliberation. We are comparably uncertain about other forms of deliberation, and especially about deliberation in a legislative setting. In his analysis of legislative deliberation, Dennis Thompson affirms that "the general conclusion of surveys of the empirical research so far is that taken together the findings are mixed or inconclusive" (499).

But although they are comparably uncertain, jury and legislative deliberation are practically different, insofar as the bad epistemic effects of the latter can be revised and eventually corrected in the long run by resorting to the same (or to improved) deliberative means. Though deliberation might sometimes lead to bad laws, the lawmakers can deliberate about those laws again, and thus come up with better ones. This explains why epistemic arguments in favor of deliberative democracy depend on a temporal proviso: legislative deliberation is epistemically justified, but only diachronically so. In the long run, bad deliberative decisions can be deliberatively unmade.

The temporal proviso does not apply to jury deliberation. Unlike laws, verdicts cannot be revised and corrected through the same deliberative means. Jurors do not have the opportunity to deliberate about the same case twice. Even when the decision

\footnotetext{
4 To my knowledge, the epistemic effects of jury deliberation have not been studied within simple majority settings, but it is safe to say that, since moving from unanimity to supermajority has no systematic epistemic effects on jury deliberation, it seems unlikely that a further move to simple majority will systematically improve deliberative reliability. Note also that (1) decision rules matter for reliability insofar as they affect the duration of the deliberative process, but there is conflicting evidence about the direction of these duration effects (e.g. Nemeth (1977) finds that unanimous juries deliberate longer than nonunanimous ones, while Brunell (2009) finds the opposite), and (2) there is no conclusive evidence about the epistemic effect of deliberative duration on the accuracy of jury verdicts. 5 Moreover, the reliability of jury deliberation hasn't be found to vary with how arguments are ordered or presented during deliberation (Takada \& Murata 2014). This suggests that there might be a general feature of deliberative interaction that exposes it to mixed epistemic effects. For a more general analysis of how voting rules influence deliberative processes, see Mackie (2018).
} 
of a jury is appealed, appellate judges deliberate about whether the law has been properly applied; they do not once again deliberate about the facts of the case. This constraint is independently desirable, because it protects defendants from the arguably more objectionable form of uncertainty accompanying double jeopardy.

However, the fact that jury deliberation cannot be applied to the same matter twice also means that the diachronically grounded epistemic optimism about legislative deliberation is not readily available in a jury setting. We therefore need a different way of positioning ourselves toward the uncertainties of jury deliberation. In the following section, I argue that epistemic humility provides us with an adequate normative stance for doing so.

\section{JURY DELIBERATION: THE EPISTEMIC HUMILITY ARGUMENT}

My epistemic humility argument proceeds in two steps. I first specify the concept of epistemic humility. I then spell out the reasons why humility offers an appropriate normative model for jury deliberation. For the purpose of this article, I will settle for a working conception of epistemic humility that brackets contentious views on the topic.

As I see it, there will be virtual consensus on three defining features of epistemic humility. ${ }^{6}$ First, epistemic humility refers to one's distinct relation to a particular body or domain of knowledge. Unlike other forms of humility and, more generally, unlike other virtues, epistemic humility does not necessarily require a global evaluation of a person's character or cognitive abilities. One can be epistemically humble in a sectorial way. For example, an engineer can be humble about the feasibility of a technical procedure, but behave arrogantly when it comes to her ability to distinguish between two types of wine. Epistemic humility does not by definition cut across different epistemic domains. Nor does it inform us in any clear way about a

\footnotetext{
${ }^{6}$ The outline of this working conception of epistemic humility is meant to preclude objections based on other (potentially controversial) conceptions.
} 
person's overall moral character or cognitive performance. A person can be epistemically humble and at the same time be reckless, immoderate, or cowardly in other respects.

Second, epistemic humility requires recognition of one's epistemic limitations. Being epistemically humble means that a person is both aware of these limitations and chooses to openly avow them. Drawing on Withcomb et al. (2015: 8), one could say that epistemic humility is about "owning one's intellectual limitations". It requires humility to see and recognize how various circumstances - say, informational gaps, cognitive biases and mistakes, unreliable epistemic procedures, bounded mental skills or intellectual defects - might affect what one knows or can claim to know.

Third, epistemic humility is relational. It does not make much sense to say that a person is humble about a piece of knowledge that concerns no one other than herself. The epistemic limitation has to involve other persons for it to require humility. Epistemic humility is relational in at least two aspects. For a person to decide whether she should be humble about a particular claim or body of knowledge, she has to assess whether the relevant limitations are uniquely hers or whether they are more widely shared by other persons as well.

Humility is also relational insofar as the epistemic limitations matter for the practical interests of other people. Humility marks out a reluctance to disregard the various ways in which one's epistemic limits might affect others. An epistemically humble person will therefore make sure to expose those limitations to relevant others. For example, a sports trainer will display epistemic humility about a training routine when she knows that, though the routine has proven effective for many people, it might under certain circumstances be detrimental to others.

To sum up, epistemic humility consists in an attitude whereby one person attends to the way in which her limited knowledge might affect another person's practical interests. The epistemically humble agent recognizes that acting on her knowledge and epistemic competences will have relevant effects on the interests of 
someone else. Humility demands that we treat our epistemic limitations and the practical interests of the relevant others as default considerations about what courses of action to take or avoid.

The evidence about jury deliberation recommends we treat it with epistemic humility. This is not only because the reliability of jury deliberation is limited by its uncertainty, but also because it represents a practice whereby the interests of relevant others - particularly, defendants' interests - stand to be affected in detrimental ways. The outcome of the deliberative procedure can give rise to a decision wherein the defendant's interest in liberty is, if not entirely forfeited, severely restricted. These two features of jury deliberation - its uncertain reliability and its strong potential for impairing the defendant's interest in liberty - require that we treat it with epistemic humility.

The problem with deliberative uncertainty is its net contribution to the verdict risks being epistemically damaging. There are two types of damages that need to be distinguished here. First, deliberation can directly increase the probability of an inaccurate verdict. This may happen in those cases in which deliberative interactions lead to strengthening certain biases the jurors might be sensitive to or when it inhibits their memories of factually relevant considerations argued during the trial proceedings.

Second, deliberation can distort the extent to which jurors' epistemically relevant beliefs direct and ultimately determine the verdict. Call this the problem of epistemically deflected verdicts. Epistemic deflection is used here by analogy with discursive or rhetorical deflection.7 It is meant to convey the situation where an otherwise epistemically adequate decision-making process is usurped by factors that are likely to distance it from one of its epistemically legitimate targets. ${ }^{8}$ In the case of jury decisions, two such relevant targets are, as indicated, reliability and accuracy. An

\footnotetext{
7 I use deflection here in its pejorative sense that includes, but is not limited to, "any slight bias or even unintended error in our vocabulary for describing reality" (Burke 1951: 208).

8 Note that (a) deflection does not depend on an agent intentionally deflecting others from an epistemically legitimate target (deflection can happen, for instance, in a context of pluralistic ignorance) and (b) deflection can work implicitly (indeed, it might be more effective if it is not explicitly noticed throughout the decision-making process).
} 
epistemically deflected verdict can, then, be characterized as a decision whose content is at least partly infused with epistemically dubious phenomena like group pressure, social loafing or dominant narrator effects. 9 These phenomena risk orienting one or more jurors toward a decision they do not agree with epistemically. In other words, epistemically deflecting factors increase the distance between a verdict's epistemic support and its discursive endorsement as deployed by and between jurors. Because, unlike individual voting, group deliberation elicits such phenomena, epistemically deflected verdicts ought to be considered as a distinctive effect of deliberative practice. $^{10}$

If jury deliberation did not affect other people's practical interests, we would not have a stringent reason to care about its uncertainty. But deliberation does affect other people's practical interests. And although jury deliberation may incidentally affect a wide range of such interests ${ }^{11}$, its distinctive purpose is to establish whether the defendant is guilty and, by doing so, to decide if his interest in liberty should be restricted. The main reason we should care about the uncertainty of jury deliberation

\footnotetext{
9 These phenomena do not exhaust the class of epistemically unwarranted influences, but they are the most typical ones to have been empirically documented. They are also phenomena that are typically deployed in a communicative context, which explains why their deflecting influence raises a distinctive problem for jury deliberation.

${ }_{10}$ All the phenomena described above might give rise to cases of conformism, i.e. situations where individuals may sustain a majoritarian or unanimous judgment even if they disagree with it. For an analysis of the risk of conformism in interactive groups, see Pettit \& List (2011: $119 \mathrm{ff}$.).

${ }_{11}$ Deliberation might, for example, affect the jurors' interest in their peace of mind. It might also indirectly affect the victim's and the wider public's interest in feeling secure. But the legitimacy of such interests is in an important sense dependent on the defendant's interest in his liberty not being curtailed without an epistemically sound justification (in this case, without a distinctive reason as to why we should prefer deliberation over the strict aggregation of individual verdicts). Thus, jury deliberation can be justified even if jurors feel anxious about deliberating and even if the victim or the wider public feels insecure about its outcome. Unless the jurors' anxiety and the victim's or the public's fear are ultimately about jury deliberation getting the verdict wrong - either by increasing the probability of convicting the innocent or the likelihood of acquitting the guilty - neither anxiety nor fear are expressive of legitimate interests that require protection. More generally, it is hard to imagine a case where jury deliberation should prioritize other practical interests over the defendant's legitimate interests. I take the defendant's interest in not having his liberty curtailed without having a distinctive reason for preferring deliberation over strict aggregation to be such a (suitably qualified) legitimate interest.
} 
resides in its potentially unwarranted impact on the defendant's interest in liberty. ${ }^{12}$ As indicated, deliberation can generate such an impact either by undermining the accuracy and reliability of the verdict or deflecting its real epistemic support.

Being humble about jury deliberation starts with recognizing that, given its limitations, it is not the best available procedure we can readily resort to in the context of jury trials. Though jury deliberation is plausibly better than random, we know that, on the whole, it is not better than the aggregation of the jurors' individual verdicts. Hiding the fact that deliberation and verdict aggregation are epistemically equivalent boils down to unjustifiably bolstering the merits of the first and downplaying the qualities of the second.

Epistemic humility further requires that we refrain from actively imposing deliberation as the best available procedure for deciding the result of a jury trial. Such imposition would amount to discarding all the evidence we have about the equivalence between deliberation and the aggregation of jurors' individual verdicts. By doing so, we would treat deliberation as more efficacious than it really is.

Note that humility does not require that we dismiss deliberation entirely. Doing so would downplay the limits of deliberation more than the evidence allows. It would not be the humble, but the skeptical thing to do. Rather, given that there is no better procedure than group deliberation or individual voting readily available in the jury trial context, and that both procedures are, on the whole, epistemically equivalent, all that humility requires is that we refrain from imposing deliberation (or, for that matter, voting) as the best available procedure for reaching the verdict.

To count as a genuine attitude, humility about jury deliberation should be translated into a series of fairly specific practical requirements. ${ }^{13}$ First, jurors should be made aware of and come to recognize that deliberating is not, on the whole, a reliable

12 With strict evidential rules or the "beyond a reasonable doubt" standard, the procedural structure of the trial is generally known to lean in favor of the defendant. This institutional fact can be interpreted as a virtual consensus that the defendant's interest in liberty deserves special protection when confronted with the coercive apparatus of the criminal justice system. ${ }_{13}$ These practical commitments are inspired by and structurally analogous to the ones that Abraham Schwab (2012) defends for epistemic humility in the context of medical practice. 
decision-making procedure, which means carefully presenting them with the existing empirical evidence on jury deliberation in a way that underlines its epistemic drawbacks and benefits. This could be done, for example, through special jury instructions that are given to and discussed with the selected jury members prior to the trial.

Second, the defendant herself should be informed that jury deliberation is uncertain. In particular, she has the right to know that the deliberation can directly undermine the epistemic quality of a verdict. Informing the defendant that deliberation comes with its own risks is a requirement that a humble penal institution will not (and should not) avoid.

Third, humility demands that jurors refrain from adopting decisional methods that are not evidentially supported or that creatively break with existing deliberative rules. A jury should avoid changing its decision-making strategy several times during the deliberative process because some its members have the impression that trying a different decision-making strategy might be more suitable for the case under consideration. Innovation has its place in the jury room, but it should be tried out in experimental conditions before actually being generally enforced.

Fourth, and more distinctively, humility about deliberation requires that the defendant - toward whom the deliberative practice is ultimately targeted - consent to the jurors' deliberation. This might be the most contentious implication of the humility argument, and I will defend it in the following section. For now, suffice it to say that, in the absence of the defendant's consent, the humility argument would remain idle. Epistemic humility about jury deliberation requires that special consideration be given to the defendant's consent because deliberation will most seriously affect the 
defendant's interest in liberty ${ }^{14}$ and because deliberation is not uniquely reliable in prompting a decision that will affect that interest. ${ }^{15}$

\section{JURY DELIBERATION AS A WAIVABLE RIGHT}

I have claimed that humility about jury deliberation implies that the defendant should be given the opportunity to consent to its enforcement or not. The purpose of this section is to delineate an institutional mechanism for doing so. I suggest that humility can be expressed by turning jury deliberation from a mandatory rule of jury trials to a waivable right of the defendant. If such a right is to express the defendant's consent to jury deliberation transparently, it should be granted unconditionally.

Today, defendants have no choice between a jury trial, in which their verdict is reached deliberatively, and a jury trial wherein this is not the case. Introducing a waivable right to jury deliberation means that, at the beginning of the trial proceedings, the defendant is presented with two options. Either her verdict will be decided through jurors' voting separately on the verdict - that is, without any prior group deliberation or it will be decided, as it is now, by means of jury deliberation. The choice formalized by such a waivable right is one between a deliberative and a non-deliberative verdict. ${ }^{16}$

There are two worries to this proposal that need to be discarded from the start. A non-deliberative decision might appear problematic because it seems to both encourage rushed verdicts and, in jurisdictions with unanimity rules ${ }^{17}$, increase the probability of hung juries. The first worry pertains to insufficiently reasoned verdicts;

\footnotetext{
${ }^{14}$ For a discussion of the primacy of the defendant's interest in the justification of jury deliberation, see fn. 11 above and the corresponding discussion in the text.

15 As noted, deliberation is not uniquely reliable when compared to a strictly aggregative procedure (verdict via voting).

16 In choosing whether to waive her jury deliberation right, the defendant could and should be assisted by her lawyer, who would give her access to a fuller picture of the pros and cons of jury deliberation.

${ }_{17}$ Some jurisdictions do not require unanimity (e.g. Oregon requires a 10-2 majority for all offenses except murder; the majorities in England and Wales are of 10-2 or 10-1, and in Scotland it is of 8-7).
} 
the second worry concerns the inefficiency of non-deliberative verdicts under a unanimous decision rule.

Both worries can be countered institutionally, by modifying the decision rule of non-deliberative verdicts from unanimity (in those jurisdictions where unanimity is the rule) to a two-level super-majority rule. By two-level, I mean that jurors vote both on the content of their verdict (guilty/not-guilty) and on whether their verdict is definitive.

The decision-making procedure for non-deliberative verdicts would unfold as follows. ${ }^{18}$ After individually casting their initial verdicts, jurors are notified whether the super-majority rule is satisfied, without at this stage being told what the distribution of individual verdicts is. If there is a super-majority, jurors are asked whether their vote is definitive. If a jury super-majority agrees that its votes are definitive, voting stops with a valid final verdict. If there is no jury super-majority endorsing the same verdict, jurors are asked if their decision is definitive. If a super-majority decides its verdict is definitive despite the absence of a super-majority endorsing the same verdict, a hung jury is declared. Alternatively, jurors cast a new (potentially different) vote. After each verdict voting stage, jurors are asked whether their decision is definitive, and voting stops whenever a super-majority of jurors agree their votes are definitive. If the distribution of votes changes such that it satisfies the super-majority rule and there is a super-majority of jurors who agree that their votes are definitive, a valid final verdict is declared. At no stage of the process are jurors informed about what the distribution is. To safeguard the strictly aggregative nature of non-deliberative verdicts, jurors are only informed whether the distribution allows for a valid verdict under the super-majority rule.

Super-majorities offer a mechanism for reducing the probability of a hung jury. ${ }^{19}$ First, they eliminate the possibility of a hung jury that none of the jurors can control. Second, they enable jurors to give minimal consideration to the certainty of

\footnotetext{
${ }^{18}$ All jurors are informed of this decision-making procedure before casting their initial votes.

19 All things equal, the probability of a hung jury will be reduced with the size of the supermajority.
} 
their verdict and they provide them with reasonably sufficient time for rethinking the justification for individual verdicts whenever there is substantial disagreement over the final verdict, i.e. whenever the super-majority rule is not satisfied.

More generally, super-majority rules in non-deliberative settings are on balance preferable to the relevant alternatives. They are epistemically preferable to a simple majority rule, since, for juries whose size is fixed, a decision supported by a larger number of jurors is, all else equal, more likely to be accurate (List 2003; Nitzan \& Paroush 1984). Super-majorities are also preferable to the unanimity rule, because they comparatively decrease the probability of a hung verdict and because the main epistemic rationale of the unanimity rule (which is that of motivating jurors to deliberate) disappears in non-deliberative settings. ${ }^{20}$

Two additional worries might be raised about this non-deliberative scheme. The first is that giving jurors even very limited information about the decisional distribution will surreptitiously create a cascade-like dynamic and reintroduce the risk of deflected verdicts. This worry is unwarranted. Cascades can be informational, reputational, or both (Kuran \& Sunstein 1999). Informational cascades happen when people who lack beliefs of their own adopt the apparent beliefs of others. Reputational cascades happen when people adhere to a belief to earn other people's social approval. The non-deliberative option avoids both reputational and informational cascades. It avoids the former because jurors' views in the non-deliberative setting are anonymous, and thus the probability of their reputation being at stake is negligible. Their anonymity means that they have no reputation to protect.

The non-deliberative scheme avoids informational cascades because knowing only whether the verdict distribution is conclusive will generally be insufficient for any apparent verdict to be promoted. The only case where a specific verdict will be promoted is when the initial distribution is conclusive and is endorsed as such. But

20 For an epistemic critique of unanimity, see Feddersen \& Pesendorfer (1998), and (more widely) Schwartzberg (2013), chapters 3-4. 
note that, even in this scenario, all initial votes are "cascade-proof", and that the overall decisional distribution does not provide jurors with any further reason for changing their verdict. If, on the other hand, jurors decide to keep their verdict, they will most likely do so based on their initial reasons and not because they know everyone voted the same.

The other worry is that overall verdict inconclusivity does not provide a reason for changing one's individual verdict. No juror knows why the others voted the way they did, so inconclusivity does not per se generate new reasons for changing one's verdict. But the point of informing jurors about the overall vote distribution is not verdict revision. It is verdict reconsideration. When the vote distribution is inconclusive, jurors are given an opportunity to reconsider, not a reason to revise their verdict. They are, in other words, invited to engage in a deeper process of "private deliberation" (Goodin 2003) and think about the reasons why other jurors might have voted differently. Even if no such reasons are found, privately reassessing one's verdict is desirable in itself.

Turning jury deliberation into a waivable right expresses a trade-off between the risks that come with two kinds of verdicts. Deliberative verdicts create a distinctive risk of epistemically deflected decisions. Non-deliberative verdicts raise the risk of an epistemically shallow decision. This refers to decisions that waste the potential advantages - such as improving the quality of the jurors' memories, minimizing their biases or increasing the accuracy of their evidence evaluations - that might accompany jury deliberation and will be lost by waiving it.

The problem is that we cannot settle this trade-off in advance. Given the pervasively mixed state of the evidence documented in the previous section, we cannot decide ex ante whether jury deliberation is more likely to improve the quality of the verdict or more likely to distort it. Put differently, we cannot weigh the risk of an epistemically shallow verdict more than that of an epistemically deflected one. A jury 
deliberation waiver might not settle the trade-off, but will, at least, make it public and do so in an adequately humble way.

My proposal may appear to be either practically redundant or epistemically idle. It is neither. The proposal might seem redundant for someone who, recalling that defendants can already waive their right to trial by jury, would interpret the absence of such a waiver as expressive of defendants' implicit preference for a group over individual judgment: defendants who refuse to consent to jury deliberation can already do so indirectly, by opting for a bench trial. It would then be redundant to ask for the same consent twice.

This argument is defective because we cannot draw any straightforward inference from an unwaived right to trial by jury to the defendant's implicit consent to jury deliberation. This is because defendants do not actually have control over whether their trial is decided by a jury. In most cases, the choice of a bench trial is conditional on the prosecutor's and, in some cases, the judge's consent. ${ }^{21}$ There will be at least some cases in which a defendant might want to waive their right to trial by jury, but will not be allowed to do so by the prosecutor, the judge or both. Therefore, the deliberative waiver would not be redundant, in that it would merely restate the consent that was initially given by not waiving the right to jury trial.

But suppose that the defendant's jury trial waiver were unconditional. Even in such a case, inferring her implicit consent to jury deliberation from an explicit choice of a jury trial would be mistaken. There is a sense in which such an argument would be generally problematic. It appeals to implicit consent, an idea that has often been criticized for being empty at best and cynical at worst. ${ }^{22}$ Moreover, the argument would fail because the defendant can legitimately hold on to her right to jury trial for reasons that are independent of her endorsement of jury deliberation - for instance, because she thinks that the judge might have an unwarranted bias toward cases like hers or

\footnotetext{
${ }^{21}$ Only 6 states allow jury trials to be waived unconditionally (Welty \& Pattel 2014). For an argument in favor of such unconditional waivers, see Stein \& Segal (2016). 22 Maloberti (2010).
} 
because she prefers to be judged by her peers while at the same time resenting the fact that a biased juror could be in a position to control the verdict formation process. If these latter reasons do not entail consent to jury deliberation, then a jury deliberation waiver is not redundant.

Though non-redundant, my proposal may seem epistemically idle. This is the case, if one thinks that turning deliberation into a waivable right will by itself do nothing to improve its reliability. However, the epistemic idleness worry misconstrues the point of my humility argument. Mere epistemic humility cannot increase the probability of accurate verdicts, but this is not what humility is meant to do. Remember that epistemic humility is not about solving the issue of epistemic disagreement or dissolving the uncertainty that comes with it. Rather, humility is about recognizing one's epistemic limitations, while at the same time trying to overcome them as much as possible. Humility might help foster felicitous conditions for reaching an accurate verdict, but it cannot guarantee it.

All that humility requires is that the penal institution avoid unilaterally imposing jury deliberation. Thus construed, a humble penal institution is not meant to eliminate our uncertainty about jury deliberation. It is only supposed to reflect that uncertainty as accurately and transparently as possible. An epistemically humble agent - whether individual jurors, criminal justice officials or lay citizens - can, at best, merely hope that jury deliberation will become more reliable.

My proposal is indeed idle insofar as a non-deliberative verdict cannot, on the whole, be guaranteed to be epistemically superior. But what a jury deliberation waiver can do is to protect the defendant's interest in receiving an epistemically non-deflected verdict. As explained, this refers to a verdict whose accuracy cannot be doubted because of the potential group pressure that might come with jury deliberation. Thus construed, my waiver proposal is not epistemically idle. A defendant who opts for a non-deliberative jury can at least be certain that her verdict reflects the actual judgment of each individual juror, and that no juror has been pressured into accepting 
a group decision she disagrees with. As the evidence quoted in the previous section shows, we have good reasons to consider that verdicts are sometimes distorted through deliberation.

One might perhaps contend that the risk of an epistemically deflected verdict is not substantial enough to justify such a reform. But such a contention would be problematic. In their analysis of the impact of group deliberation on individual jurors' decisions in 367 felony juries, Waters \& Hans (2009) found that $38 \%$ of the jurors would have voted against their jury's decision. This means that more than one third of the jurors (there were 3,500 in total) did not agree with, but eventually voted in favor of the majority's decision. The reasons why "conforming dissenters" disagreed with the final verdict were both substantive, in that they "were skeptical that all the relevant evidence was presented in the case" (Waters \& Hans 2009: 527), and procedural, insofar as they were dissatisfied with the way in which the trial was conducted. ${ }^{23}$ The authors conjecture that the reason why these jurors ultimately conformed is most plausibly linked to group pressure. Being in a minority made it socially more difficult to oppose the majority view.

This latter finding provides a plausible ground for thinking that the risk of an epistemically deflected verdict - that is, a verdict determined by social pressure or other epistemically unwarranted phenomena - is both real and substantial. Note that jurors who most often change their minds about the verdict are not the least accurate ones, but the least confident (Simon 2012). Worse still, jury deliberation has been found to inflate jurors' confidence in judgments that are not evidentially supported (Simon 2012: 201). Epistemically deflected verdicts may not happen in all cases, but the social pressure that comes with group deliberation does not make their number negligible.

23 The most worrying figure is that $60 \%$ of the conforming dissenters voted to convict against their private judgment. See Waters \& Hans (2009): 537. 
My proposal might seem less important for juries that follow a (super)majority, not unanimity decision rule. One might contend that a (super)majority rule already weakens the effects of social pressure, while at the same time maintaining some of the potential advantages of group deliberation. But this contention misses the fact that social pressure does not always exert itself openly, and that verdicts can also be distorted by phenomena unrelated to overt pressure, but to cognitive inertia, such as social loafing or memory inhibition. Moreover, the studies on jury polarization presented in the previous section show that epistemic deflection could affect (super)majority verdicts as well, not just unanimity ones. A deliberation waiver would therefore be, all things equal, justified even for juries following a (super)majority rule. ${ }^{24}$

\section{WAIVING JURY DELIBERATION: TWO OBJECTIONS}

I will now briefly consider two more general objections to my argument. ${ }^{25}$ The first targets the value of humility. The second objection concerns the structure of the proposed waiver and, more specifically, raises a worry about allowing it to be unconditionally exerted by the defendant. Both objections are defeasible - or so, at least, I will argue.

One might first worry that, even if it is not intended to generate an epistemic improvement, adopting a general attitude of humility toward the jury decision-making process might prove self-defeating or nearly so. This might happen in two ways. On a more general level, expressing humility might fall prey to a performative contradiction. As soon as a person declares that she is humble, she affirms this to be her quality or virtue. By doing so, the person puts forward a self-appreciating judgment, thereby wiping out or at least diluting the truth of her general claim to humility. Like the Cretan saying that all Cretan are liars, the putatively humble person cannot be right about her humility and be humble at the same time.

24 For a critique of majority rule arguing that it renders some votes empty (and especially those of social and racial minorities), see Taylor-Thompson (2000). 
This concern is not unassailable. There are cases in which one can be humble and assert her humility successfully - for instance, when a job applicant is asked to assess her professional weaknesses and show that she can address them appropriately. The self-defeatingness impression may also be premature. Assessing a person's humility is not a one-round game. Rather, it works as a longer-term evaluative process. We can decide whether a person is humble only once we have observed that she tends to behave in line with how she describes herself over a longer period of time. Only if the person keeps reaffirming her humility should we doubt that she is genuinely humble.

The self-defeatingness objection can be countered more directly. For my argument to remain undefeated, I can specify that the kind of humility I am referring to is not a feature of a person's character, but a virtue of the penal institution. My argument is not that individual jurors should display epistemic humility - although that would by all means be desirable - but that the trial institution should be arranged so that it expresses humility. On this account, humility is not about any one person's self-assessment; it is instead about an institutional arrangement that forbids imposing a decision-making procedure on an epistemic basis it does not actually satisfy.

The second general objection concerns the waivability proposal. One might consider that, even if my humility argument proves sound, it might not support turning jury deliberation into a waivable right of the defendant. This objection has two prongs. On the one hand, one could argue that defendants are not in any way better placed to waive jury deliberation - for example, because defendants might have a better idea that the risk of bigoted jurors seizing the deliberative process would be high in their case.

This claim is partly right, but it misses three other considerations that might, when weighed together, considerably weaken it. First, no one is ideally placed to decide whether, in any particular case, the jury deliberation process will be more likely to result in a deflected verdict or not. Second, the defendant would not be alone in exerting her waiver, since her lawyer would have a duty to assist her in making a 
decision most favorable to her interests. ${ }^{26}$ Third, and most importantly, taking humility seriously generates an obligation to have the consent of the person who stands to be most affected by the limits of our certainty. That person is the defendant, and granting her a jury deliberation waiver is tantamount to giving her the possibility to consent to its risks.

The second prong of this second objection concerns the burdensomeness of the waiver as potentially experienced by the defendant. Granting the defendant a deliberative waiver looks like asking her to gamble with her verdict and to do so at the risk of getting an inaccurate verdict either way. The choice formalized by the waiver feels like a burden, not a blessing. This worry is sensible, but ungrounded if advanced from the position where we stand today. We are already gambling with that verdict and imposing our own gambling strategy when we decide to make deliberation a mandatory rule of the jury trial. If anything, the current situation is worse, in that we pretend that the trade-off between what I called an epistemically deflected and an epistemically shallow verdict does not exist. By acting as if jury deliberation offered the best jury trial arrangement currently possible, we are merely hiding the burden, not lowering it.

\section{CONCLUSION}

My argument is that we should be humble about the reliability of jury deliberation, and that, in virtue of the obligations generated by a genuine commitment

\footnotetext{
${ }^{26}$ One might worry that defense lawyers will use waivability to gather evidence about whether deliberative or non-deliberative juries are more likely to result in acquittals and use this evidence to favor their clients. There are at least four reasons that mitigate this worry. First, since acquitting the innocent is not a problem, the worry is not about acquittals simpliciter, but about acquitting guilty defendants. But thus restated, the worry lacks conceptual space, because it cannot be raised ex ante (ex ante, no defendant can be presumed guilty). Second, using the evidence that lawyers can gather by themselves will be inevitably vulnerable to a selection bias and, as such, should be used sparingly (if at all) in advising the defendant. Third, the government can forestall the lawyers playing the system by conducting systematic studies examining whether there is a tendency for either deliberative or non-deliberative verdicts to result in more (or less) acquittals and examine whether this difference involves any verdict accuracy costs. Fourth, since there is no available evidence to show that deliberation as such increases or decreases the probability of conviction, the worry misses empirical support. I thank one of the reviewers for pressing me on this issue.
} 
to epistemic humility, we should grant the defendant a jury deliberation waiver. It is worth recalling that I take the trial by jury to be a legitimate institution, and do not call into question its overall institutional architecture.

One could imagine other more effective ways to reform jury deliberation - for example, by increasing the size and diversity of the jury or, more innovatively, by resorting to online virtual juries. These changes are not incompatible with my proposal, and they can be undertaken simultaneously. One of the comparative advantages of waivability lies in its feasibility. ${ }^{27}$ It does not need more resources than those already allocated to the jury system and it is more likely to be accepted than a technological innovation such as the virtual jury. My humility-based argument for the waivability of jury deliberation is not a blueprint for an ideal practice, but an attempt to marginally improve the status quo.

Author: Andrei Poama, Assistant Professor, Faculty of Governance and Global Affairs, Institute of Public Administration, Leiden University. Email address: a.poama@fgga.leidenuniv.nl

Acknowledgments. I would like to thank Annabelle Lever, Tom Theuns, Eliot Litalien, Briana McGinnis, Jacob Levy, Christian Nadeau, Marc-Kevin Daoust, Marc-Antoine Dilhac and Elise Rouméas, as well as participants to the Geneva Colloquium in Political Theory and the two anonymous reviewers for their very valuable comments on previous versions of this article. I am also very grateful for the institutional support granted by the Centre de Recherche en Ethique (Montreal) during the early phases of writing this article.

\footnotetext{
27 Similar to other policy proposals, the success of this one is unlikely unless actively promoted by groups and professional and non-governmental organizations that would both endorse it and have enough political leverage to push for the corresponding legislative reforms.
} 


\section{REFERENCES}

1. Bray, R.M., Noble, A.M. 1978. 'Authoritarianism and decisions of mock juries: Evidence of jury Bias and Group Polarization,' Journal of Personality and Social Psychology. 36(12): 1424-1430.

2. Brunell, T.L., Dave, C., Morgan, N.C. 2009. 'Factors Affecting the Length of Time a Jury Deliberates: Case Characteristics and Jury Composition,” Review of Law and Economics. 5(1): 554-578.

3. Burke, K. 1951. 'Rhetoric - Old and New,' The Journal of General Education, 5(3): 202-209.

4. Carretta, T.R., Moreland, R.L. 1983. 'The direct and indirect effects of inadmissible evidence,' Journal of Applied Social Psychology. 13: 291-309.

5. Cowan, C.L., Thompson, W.C., Ellsworth, P.C. 1984. 'The Effects of Death Qualification on Jurors' Predisposition to Convict and on the Quality of Deliberation,' Law and Human Behavior, 8(1/2): 53-79.

6. Devine, D.J. et al. 2001. 'Jury decision making: 45 years of empirical research on deliberating groups,' Psychology, Public Policy, and Law, 7, 622-727.

7. Devine, D.J. 2012. Jury Decision Making: The State of the Science. NYU Press.

8. Diamond, S.S., Levi, J.N. 1996. 'Improving Decisions on Death by Revising and Testing Jury Instructions,' Judicature, 79: 224-232. 
9. Diamond, S.S. 1997. 'Illuminations and Shadows from Jury Simulations,' Law and Human Behavior, 21(5): 561-571.

10. Elwork, A., Sales, B.D. 1985. 'Jury Instructions,' in Kassin, S.M., Wrightsman, L.S. (eds.). The psychology of evidence and trial procedure, 280-297. Beverly Hills, CA: Sage.

11. Feddersen, T., Pesendorfer, W. 1998. 'Convicting the Innocent: The Inferiority of Unanimous Jury Verdicts under Strategic Voting,' American Political Science Review, 92(1): 23-35.

12. Forston, R.F. 1975. 'Judge's instructions: A quantitative analysis of jurors' listening comprehension,' Today's Speech, 18: 34-38.

13. Forston, R.F. 1975. 'Sense and non-sense: jury trial communication,' Brigham Young University Law Review, 601-637.

14. Goodin, R. 2003. Reflective Democracy. Oxford University Press.

15. Haegerich, T.M., Salerno, J.M., Bottoms, B.L. 2013. 'Are the Effects of Juvenile Offender Stereotypes Maximized or Minimized by Jury Deliberation?,' Psychology, Public Policy, and Law, 19(1): 81-97.

16. Hannaford-Agor, P. Hans, V.P., Munsterman, C.T. 1999. 'How Much Justice Hangs in the Balance? A New Look at Hung Jury Rates,' Judicature, 83(2): 5967.

17. Hastie, R., Penrod, S.D., Pennigton, N. 1983. Inside The Jury. Harvard University Press.

18. Hazlett, A. 2012. 'Higher-Order Epistemic Attitudes and Intellectual Humility,' Episteme, 9(3): 205-223.

19. Hedden, B.R. 2017. 'Should Juries Deliberate?' Social Epistemology. A Journal of Knowledge, Culture, and Policy, 31(4): 368-386.

20. Hirst, W., Coman, A., Stone, C.B. 2012. 'Memory and Jury Deliberation. The Benefits and Costs of Collective Remembering,' in Sinnot-Armstrong, W.P., Nadel, L. Memory and Law. Oxford University Press. 
21. Ho, H.L. 2013. 'Virtuous Deliberation on the Criminal Verdict,' in Amaya, A., Ho, H.L. Law, Virtue and Justice. Hart Publishing.

22. Izzett, R.R., Leginski, W. (974. 'Group discussion and the influence of defendant characteristics in a simulated jury setting,' Journal of Social Psychology, 93: 271-279.

23. Kalven, H., Zeisel, H. 1966. The American jury. Boston: Little: Brown.

24. Kaplan, M., Miller, L. E. 1978. 'Reducing the Effects of Juror Bias,' Journal of Personality and Social Psychology, 36(12): 1443-1455.

25. Kerr, N.L, Niedermeier, K.E., Kaplan, M.F. 1999. 'Bias in Jurors vs. Bias in Juries: New Evidence from the SDS Perspective,' Organizational Behavior and Human Decision Processes. 80(1): 70-86.

26. Kerr, N.L. 1981. 'Social transition schemes: Charting the group's road to agreement,' Journal of Personality and Social Psychology, 41: 684-702.

27. Kerwin, J., Shaffer, D. R. 1994. 'Mock Jurors Versus Mock Juries: The Role of Deliberations in Reactions to Inadmissible Testimony,' Personality and Social Psychology Bulletin, 20(2): 153-162.

28. Kramer, G.P., Kerr, N.L., Carroll, J.S. 1990. 'Pretrail publicity, judicial remedies, and jury bias,' Law and Human Behavior, 14: 409-438.

29. Kraus, D.A., Lee, D.H. 2003. 'Deliberating on the dangerousness and death: jurors' ability to differentiate between expert actuarial and clinical predictions of dangerousness,' International Journal of Law and Psychiatry. 26: 113-137.

30. Kuran, T., Sunstein, C. 1999. 'Availability Cascades and Risk Regulation,' Stanford Law Review, 51(4): 683-768.

31. Lieberman, J.D, Sales, B.D. 'What social science teaches us about the jury instruction process,' Psychology, Public Policy, and Law, 3(4): 589-644.

32. London, K., Nunez, N. 2000. 'The Effect of Jury Deliberations on Jurors' Propensity to Disregard Inadmissible Evidence,' Journal of Applied Psychology, 85(6): 932-939. 
33. Lynch, M., Haney, C. 2009. 'Capital Jury Deliberation: Effects on Death Sentencing, Comprehension, and Discrimination,' Human Law and Behavior, 33: 481-496.

34. MacCoun, R. 2002. 'Comparing micro and macro rationality' in Gowda, R.M.V., Fox, J. (eds). Judgments, decisions, and public policy. Cambridge University Press: 116-137.

35. Mackie, G. 2018. 'Deliberation and Voting Entwined,' in Bächtiger, A., Dryzek, J.S., Mansbridge, J., Warren, M. (eds). The Oxford Handbook of Deliberative Democracy. Oxford University Press: 218-236.

36. Maloberti, N. 2010. 'The Fallacy of Implied Consent,' Journal of Value Inquiry, 44(4): 469-476.

37. McCoy, Monica L., Nunez, N., Dammeyer, M. M. 1999. 'The Effects of Jury Deliberation on Jurors' Reasoning Skills,' Law and Human Behavior, 23(5): $557-575$.

38. Nemeth, C. 1977. 'Interactions Between Jurors as a Function of Majority vs. Unanimity Decision Rules,' 7: 38-56.

39. Nunez, N., McCrea, S.M. Culhane, S.E. 2011. 'Jury Decision Making Research: Are Researchers Focusing on the Mouse and Not the Elephant in the Room?,' Behavioral Sciences and the Law, 29(3): 439-451.

40. Otto, A.L. Penrod, S.D., Dexter, H.R. 1994. 'The Biasing Impact of Pretrial Publicity on Juror Judgments,' Law and Human Behavior, 18(4): 453-469.

41. Pritchard, M.E., Keenan, J.M. 2002. 'Does Jury Deliberation Really Improve Jurors' Memories?,' Applied Cognitive Psychology, 16: 589-601.

42. Salerno, J.M., Mccauley, McCauley, M.R.. 2009. 'Mock Jurors' Judgments about Opposing Scientific Experts: Do Cross-Examination, Deliberation and Need for Cognition Matter?,' American Journal of Forensic Psychology, 27(3): $1-24$. 
43. Salerno, J.M., Diamond, S.S. 2010. 'The promise of a cognitive perspective on jury deliberation,' Psychonomic Bulleting \& Review. 17(2): 174-179, 174.

44. Sanders, L. 1997. 'Against Deliberation,' Political Theory, 25(3): 347-376.

45. Sandys, M., Dillehay, R.C. 1995. 'First-ballot votes, pre-deliberation dispositions, and final verdicts in jury trials,' Law and Human Behavior, 19: $175-195$

46. Schwab, A. 2012. 'Epistemic Humility and Medical Practice: Translating Epistemic Categories into Ethical Obligations,' Journal of Medicine and Philosophy, 37(1): 28-48.

47. Schwartzberg, M. 2013. Counting the Many: The Origins and Limits of SuperMajority Rule. Cambridge University Press.

48. Segal, U., Stein, A. 2006. 'Ambiguity Aversion and the Criminal Process,' Notre Dame Law Review, 100: 1-68.

49. Severance, L.J, Loftus, E.F. 1982. 'Improving the Ability of Jurors to Comprehend and Apply Criminal Jury Instructions,' Law \& Society Review, 17(1): 153-198.

50. Simon, D. 2012. In Doubt: The Psychology of the Criminal Justice Process. Harvard University Press.

51. Spanos, N.P., Dubreuil, S.C; Gwynn, M.I. 1991. 'The effects of expert testimony concerning rape on the verdicts and beliefs of mock jurors,' Imagination, Cognition and Personality, 11: 37-51.

52. Stasser, G. \& Davis, J.H. 1981. 'Group decision-making and social influence: A social interaction sequence model,' Psychological Review, 88: 523-551.

53. Steblay, N.M., Besirevic, J., Fulero, S.M., Jimenez-Lorente, B. 1999. 'The Effects of Pretrial Publicity on Jury Verdicts: A Meta-Analytic Review,' Law and Human Behavior, 23(2): 2\&9-235. 
54. Steblay, N., Hosch, H.M., Culhane, S.E., McWethy, A. 2006. 'The Impact on Juror Verdicts of Judicial Instruction to Disregard Inadmissible Evidence: A Meta-Analysis,' Law and Human Behavior, 30: 469-492.

55. Sunstein, C. 2006. Infotopia: How Many Minds Produce Knowledge. Oxford University Press.

56. Takada, M., Murata, K. 2014. 'Accentuation of Bias in Jury Decision-Making,' Group Processes \& Intergroup Relations, 17(1): 110-124.

57. Taylor-Thompson, K. 2000. 'Empty Votes in Jury Deliberations,' Harvard Law Review, 113(6): 1261-1320.

58. Thompson, W.C., Fong, G.T., Rosenhan, D.L. 1981. 'Inadmissible evidence and juror verdicts,' Journal of Personality and Social Psychology, 40: 453-463.

59. Thompson, D. 2008. 'Deliberative Democratic Theory and Empirical Political Science,' Annual Review of Political Science, 11: 497-520.

6o. Waters, N.L., Hans, V.P. 2009. 'A Jury of One: Opinion Formation, Conformity, and Dissent on Juries,' Journal of Empirical Legal Studies, 6(3): 513-540.

61. Welty, J.B., Patel, K.K. 2014. 'Understanding North Carolina's Proposed Constitutional Amendment Allowing Non-Jury Felony Trials,' UNC School of Government Report.

62. Wissler, R.L., Saks, M.J. (1985). 'On the inefficacy of limiting instructions. When jurors use prior conviction evidence to decide on guilt,' Law and Human Behavior, 9(1): 37-48.

63. Wheatmann, S.R., Shaffer, D.R. 2001. 'On Finding for Defendants Who Plead Insanity: The Crucial Impact of Dispositional Instructions and Opportunity to Deliberate,' Law and Human Behavior, 25(2): 167-183. 